\title{
A percepção dos psicólogos sobre o racismo institucional na saúde pública
}

The perception of psychologists about institutional racism in public health

Natália Oliveira Tavares', Lorena Vianna Oliveira², Sônia Regina Corrêa Lages³

\footnotetext{
1 Mestranda em Psicologia pela Universidade Federal de Minas Gerais (UFMG) - Belo Horizonte (MG), Brasil. nataliaotavares@yahoo.com.br

${ }^{2}$ Graduanda em Psicologia pela Universidade Federal de Minas Gerais (UFMG) - Belo Horizonte (MG), Brasil. lorenavoliveira@gmail.com

${ }^{3}$ Doutora em Psicossociologia das Comunidades e Ecologia Social pela Universidade Federal do Rio de Janeiro (UFRJ) - Rio de Janeiro (RJ), Brasil. Professora Adjunta de graduação e pós-graduação no curso de Psicologia da Universidade Federal de Minas Gerais (UFMG) - Belo Horizonte (MG), Brasil. sonialages@ig.com.br.
}

RESUMO: $O$ artigo apresenta os resultados de uma pesquisa que teve como objetivo investigar a percepção dos psicólogos a respeito do racismo nas instituições de saúde. Esses profissionais integram o setor de psicologia de três hospitais públicos situados na cidade de Belo Horizonte. A metodologia fez uso da entrevista semiestruturada e da análise de conteúdo. Os resultados apontam a ausência de um olhar crítico dos profissionais sobre as relações étnico-raciais e suas implicações no campo da saúde, o que reproduz a ideologia da igualdade social no país, não contribuindo, assim, para com as ações promotoras da equidade.

PALAVRAS-CHAVE: Psicólogos; Racismo institucional; Saúde; População negra.

\begin{abstract}
This article presents the results of a study that aimed to analyze the perception of psychologists about racism in health institutions. These professionals integrate psychology sectors of three hospitals located in the city of Belo Horizonte. The methodology uses semi-structured interviews and content analysis. The results indicate the absence of critical view among professionals regarding ethnic-racial relations and their implications to the health field, reproducing the ideology of social equality in the country, what, in turn, does not contribute to the implementation of actions that promote equity.
\end{abstract}

KEYWORDS: Psychologists; Institutional racism; Health; Black population 


\section{Apresentação}

O racismo institucional, compreendido como o fracasso coletivo no atendimento com qualidade aos grupos sociais estigmatizados pela cor ou pela etnia, afeta, de forma significativa, a população negra no campo da saúde. A falsa democracia racial no Brasil, que "invisibiliza" o racismo, e, em consequência, as doenças que atingem de forma mais específica esses coletivos, dificultando o acesso aos serviços de saúde assim como a qualidade da atenção à saúde, tem sido determinante importante nos perfis de adoecimento e morte dos afrodescendentes. (LOUREIRO; ROZENFELD, 2005; LOPES, 2005a; BATISTA et al, 2005).

Apesar de a Política Nacional de Saúde Integral da População Negra (2010) reconhecer que as condições de vida dessa população resultam de injustos processos sociais, culturais e econômicos da história do País, e que a persistência dessa situação é observada nas altas taxas de mortalidade materna e infantil, na maior prevalência de doenças crônicas e infecciosas e nos graves índices de mortalidade de jovens e adultos em razão da violência urbana, drogas e álcool, os estudos sobre a temática apontam para a fragilidade das ações em prol da superação dessa situação.

As experiências desiguais ao nascer, viver e morrer são analisadas por Lopes (2005), que argumenta que a pobreza tem cor e que ela, dentre uma série de campos, atinge de forma visível e concreta a saúde dos afro-brasileiros, apesar de se constituir como um direito humano de acesso universal e igualitário. Ilustra a autora, com dados da pesquisa nacional sobre Discriminação Racial e Preconceitos de Cor no Brasil (2003), que:

3\% da população brasileira já se percebeu discriminada nos serviços de saúde. Entre as pessoas negras que referiram discriminaçâo, $68 \%$ foram discriminadas no hospital, 26\% nos postos de saúde e $6 \%$ em outros serviços nâo especificados. Em sua maioria, o agente discriminador foi o médico e, ainda que isto tenha sido percebido, poucos buscaram denunciar o ato. Entre aqueles que o fizeram, ninguém relatou ter sido informado sobre as providências tomadas pela instituição para reverter o quadro. (LOPES, 2005, p.20).

Outros estudos (CUNHA, 1997; OLIVEIRA, 2002; LOPES, 2004; MAIO, 2005; SILVA, 2005; WERNECK, 2005; SILVA, 2009) também evidenciam essas desigualdades e destacam a importância do Movimento Social Negro e feminista na luta pela visibilidade às questóes de saúde da população negra e da mulher negra, de forma específica. A adoção de políticas públicas voltadas para o atendimento integral da saúde da população negra iniciou-se a partir da formação do Grupo de Trabalho Interministerial para a Valorizaçáo da População Negra nos meados de 1990. Mas foi somente a partir da III Conferência Mundial de Combate ao Racismo, Discriminação Racial, Xenofobia e Intolerância Correlata, realizada em Durban na África do Sul, em 2001, que a implementação de políticas públicas voltadas para o referido campo se efetivou.

Essa situação reflete o não reconhecimento das contribuiçóes de identidades sociais desprezadas, como tão bem apresenta Honneth (2003). O autor chama atenção para os efeitos psicossociais desse não reconhecimento, argumentando como ele pode inviabilizar os sujeitos para as lutas individuais e coletivas, uma vez que ele causa profundas lesôes na autoestima, na autoconfiança e nos papéis sociais desses sujeitos. Pode-se pensar, em decorrência disso, na ausência de denúncias de preconceitos e discriminação recebidos nos hospitais, como aponta o estudo.

É procurando refletir e analisar sobre a responsabilidade da psicologia nesses processos sociais que este artigo apresenta parte de uma pesquisa de iniciação científica, que recebeu apoio da FAPEMIG e foi realizada em centros de saúde da cidade de Belo Horizonte, MG, buscando analisar os desafios no campo da saúde da população negra naquele município. No momento, foca-se na percepção de psicólogos, que trabalham em três hospitais públicos da cidade, a respeito do racismo institucional na saúde, considerando-se, de forma específica: a) o conhecimento da Lei 9.934, de 26/06/2010, que dispóe sobre a política municipal de promoção da igualdade racial, da 
Política Municipal de Saúde da População Negra, lançada em 25/04/2008, assim como as ações afirmativas desenvolvidas pela Secretaria de Saúde do município; b) o conhecimento sobre o quadro de morbimortalidade da população negra; c) a percepção do racismo nas relaçóes entre os gestores/empregados dos centros de saúde e os usuários do sistema.

A pesquisa foi aprovada pelo Comitê de Ética da UFMG, conforme Parecer ETIC 0587.0.203.000-10.

\section{Metodologia}

A pesquisa fez uso da entrevista semiestruturada (MINAYO, 1993) e da análise de conteúdo (BARDIN, 2002) como ferramenta para interpretação dos dados. Ela foi realizada em três hospitais públicos situados na cidade de Belo Horizonte e entrevistou sete psicólogos que integram o setor de psicologia dos referidos centros de saúde. Quando for necessário apresentar a fala dos sujeitos entrevistados no texto, eles serão identificados por letras maiúsculas.

Como a participação na entrevista foi voluntária, em um dos hospitais, quatro psicólogos se ofereceram para participar. Nos outros dois, cada setor de psicologia foi representado por um profissional.

As singularidades das entrevistas permitiu identificar os seguintes núcleos temáticos: (a) percepção do racismo institucional; (b) iniquidade em saúde; (c) conhecimento sobre as leis e açôes afirmativas em prol da promoção da igualdade racial; (d) interpretação dos psicólogos sobre o racismo; (e) existência de preconceitos e discriminação dentro dos centros de saúde; efeitos psicossociais do racismo; (f) papel da psicologia frente ao racismo institucional na saúde.

Em contrapartida à disponibilidade dos centros de saúde para a pesquisa, será oferecida aos profissionais daqueles centros a participação em um projeto de extensão a ser desenvolvido a partir de outubro de 2012 com o objetivo de criar um espaço de debate para se discutir o racismo institucional na saúde.

\section{Apresentação e discussão dos dados}

A erradicação do racismo institucional na atenção integral à saúde da população negra no SUS e a implementação da Política Nacional e Municipal de Atenção à Saúde Integral da População Negra integram as diretrizes do Plano Municipal de Igualdade Racial da Prefeitura de Belo Horizonte (2009). Seus objetivos vão desde a formação, capacitaçáo e treinamento dos profissionais de saúde para o afastamento das práticas racistas; promoção de açōes de prevenção e atenção à saúde da população negra com foco nas doenças como anemia falciforme, diabetes, hipertensão arterial, DST-AIDS, pré-natal e gravidez precoce; até a produção de pesquisas e divulgação de informações sobre a saúde desses coletivos.

Por outro lado, dentre os princípios que regem o Código de Ética do Conselho Federal de Psicologia (2005, p.7) destacam-se, no presente contexto, aqueles que enfatizam que o psicólogo baseará o seu trabalho em: (a) promoçấo da dignidade e integridade do ser humano, apoiados nos valores que preconizam a Declaração Universal dos Direitos Humanos; (b) promoção das pessoas e coletividades, contribuindo com a eliminação de negligência, exploração, discriminação e opressão; e (c) responsabilidade social, analisando de forma crítica e histórica a realidade político-econômica e social-cultural do País.

Torna-se evidente a responsabilidade que tem o profissional psicólogo em centros de saúde pública no que diz respeito ao combate ao racismo, uma vez que ele lida diretamente com sujeitos e coletivos que sofrem diversos e diferentes tipos de opressão, preconceitos e discriminaçáo, o que afeta gravemente sua saúde mental e física.

No entanto, as relaçóes étnico-raciais no País, mais especificamente o racismo, não são problematizados, como diz A.: "Nossa, dificil, hein... eu nunca tinha parado para pensar nisto", apontando para a naturalização das desigualdades que impedem o questionamento e a promoçãa de sua visibilidade. Em outro caso, quando ele é percebido de forma clara, a reflexão se apoia num viés subjetivista e individualista, em que o sujeito tem que se implicar com os preconceitos, encontrar saídas individuais para “(...) não ficar repetindo 
estereótipos de que foi a cultura que fez isso comigo e com minha família."(B.)

O racismo possui raízes histórico-culturais, como avalia B., mas a ideologia da miscigenaçáo aparece de forma sutil em sua fala quando diz que foi muito difícil para a população negra todo esse processo:

\section{(...) ainda que fosse se misturando, ainda que} vá se misturando, eu penso que tem toda uma situação, eu não leio muito, mas eu trabalho até... a própria escuta clínica passa por isso, de ver como o sujeito se coloca. Eu tenho pacientes negros, que eu atendo aqui nesse hospital... (B.)

A miscigenação seria a saída para a opressão, a escalada para a "branquitude", os degraus por onde devem percorrer as pessoas negras que pretendem se integrar à sociedade - ideologia do século XIX que criou estratégias psicossociais para adequar o negro a uma sociedade branca e "embranquecedora" (SOUZA, 1983). Para tanto, os coletivos negros deveriam negar sua "racialidade" e identidade adotando saídas individuais e meritocráticas, a fim de se assemelharem aos brancos e, assim, serem incluídos. (BENTO, 2003; CARONE, 2003; SOUZA, 2009, 2011).

Quando a questão é vincular o racismo às instituiçóes, o tema se torna complexo, uma vez que as instituições públicas devem se pautar por princípios de igualdade na diversidade, que são integrados ao seu ambiente e reproduzidos em forma de discurso pelos gestores e funcionários.

Entretanto, nenhum dos profissionais entrevistados conseguiu definir o que seria o racismo institucional, embora fossem capazes de recitar as normas e diretrizes do SUS sobre equidade em saúde.

Os centros de saúde que possuem convênio com o SUS recebem, em sua esmagadora maioria, pessoas negras, o que faz todo sentido, e como relata B.:

\section{(...) aqui já era um hospital que mais de $80 \%$ dos pacientes dos procedimentos eram do SUS. $E$, então o que que é que eu fui vendo ao lon- go desses 16 anos, que no primeiro momento}

a grande maioria dos meus pacientes, a maior parte da população era parda, mulata, negra. Então, o que que a gente pode pensar? É que aqui sempre veio, em termos de quantidade, sempre... isso nunca foi mensurado, mas a gente lida com isso na prática, que um número muito maior de pacientes é negro. E combinando com isso um nivel sócio e econômico baixo, mais baixo.

Os estudos do IPEA sobre a saúde no Brasil apontam que, nos atendimentos e internaçôes do SUS em 2003 no País, desagregando os dados por cor/raça, a proporçâo para os negros foi de $76 \%$ e $81 \%$, respectivamente, revelando "fortes indícios do quanto a população negra é 'SUS-dependente'”. (IPEA, 2008, p.6).

Diante desse quadro, é bem preocupante o desconhecimento dos profissionais sobre as vulnerabilidades daqueles coletivos com relação à saúde: uma das pessoas entrevistadas disse que não saberia falar sobre "nenhu$m a$ " das doenças que afetam de forma mais pontual a população negra e que "nem imaginava" que essas diferenciações pudessem acontecer. Dos sete entrevistados, apenas dois assinalaram anemia falciforme como sendo mais incidente naquela população, e nenhum deles soube falar sobre outras patologias, nem mesmo as psicológicas decorrentes dos preconceitos e discriminação.

A anemia falciforme é apenas uma das doenças que deve receber a atenção dos profissionais de saúde. Outras também são mais frequentes naqueles coletivos: "hipertensão arterial, diabetes mellitus II, deficiência de G6PD, miomatose." (SAÚDE DA POPULAÇÁO NEGRA, 2005, p.36). Essas doenças possuem sintomas similares a outras doenças e se não forem diagnosticadas corretamente podem levar os sujeitos à morte.

Mas se uma série de agravos que atingem os coletivos negros é decorrente de questóes genéticas, outros são responsáveis por uma série de problemas que estão relacionados às más condiçôes de vida, como as mortes violentas, a desnutrição, o DST/HIV/AIDS, os transtornos mentais relacionados ao uso excessivo do álcool e de outras drogas. (POLÍTICA NACIONAL DE SAÚDE INTEGRAL DA POPULAÇÁO NEGRA, 2007). 
O desconhecimento dessas doenças é decorrente da invisibilidade da questão racial no Brasil, da naturalização da ideia de que somos todos iguais. Essa ideologia tem causado a morte de inúmeros cidadãos, lembrando que a falta de informaçáo dos agravos que acometem a saúde da população negra é uma das formas do racismo institucional. Este se refere aos "interesses, açôes e mecanismos de exclusão perpetrados pelos grupos racialmente dominantes". (WERNECK, 2005, p.339).

O Relatório Macpherso (1999), documento do Reino Unido sobre o tema, define o racismo institucional como:

\section{A incapacidade coletiva de uma organizaçâo em prover um serviço apropriado ou profis- sional às pessoas devido à sua cor, cultura ou origem étnica. Ele pode ser visto ou detectado em processos, atitudes e comportamentos que contribuem para a discriminação através de preconceito não intencional, ignorância, de- satenção e estereótipos racistas que prejudicam as minorias étnicas. (COMISSION..., 1999, p.2 apud WERNECK, 2005, p.340).}

Nas instituiçóes de saúde, o racismo institucional se faz presente nas políticas que ignoram os diferentes perfis de adoecimento e morte entre brancos e negros; na formação dos profissionais que não inclui o debate sobre as questóes raciais; no mau atendimento traduzido pela falta de atenção, descaso, ou por outras formas sutis de preconceito, como olhares, silêncios.

As autoras Loureiro e Rozenfeld (2005), numa pesquisa que teve por objetivo analisar as internaçóes devidas às complicaçóes da anemia falciforme com foco nos aspectos epidemiológicos e clínicos em hospitais da Bahia, Rio de Janeiro e São Paulo (no período de 2000 a 2002), apontam disparidades nas internaçóes entre os centros de saúde pesquisados. No hospital da Bahia, por exemplo, a frequência e a baixa internação são significativamente menores do que nos outros estados. A análise aponta para a possibilidade da ocorrência de subregistros dos casos ou a permanência no setor de emergência durante todo o período de cuidados hospitalares ou pelo uso incorreto da CID ou, então, "devido à grave ocorrência de baixa assistência hospitalar aos pacientes portadores de doença falciforme nesse Estado". (LOUREIRO; ROZENFELD, 2005, p.947). Muito grave, também, é o subregistro dos óbitos atribuídos à anemia falciforme, podendo significar o desconhecimento do diagnóstico dessa doença.

O racismo institucional na saúde aparece de forma sutil na linguagem e no comportamento dos funcionários, como relata um dos psicólogos entrevistados:

Pra uma pessoa negra, o atendimento é diferenciado, sabe? Ele é. Até a questão do tratar os pacientes, também eu às vezes percebo isso. $O$ carinho, né? $O$ do olho claro, do cabelo... ele tem uma atenção um pouco melhor. Não sei se pela questão estética talvez... mas, assim... tem alguma coisa que diferencia. Sempre tá ligado às questóes... às vezes as pessoas ligam à questão da marginalização mesmo. A gente recebe muitos pacientes com perfuração por arma de fogo, então assim... às vezes vem e o tratamento... é dificil a gente falar disso... (A.).

No caso de uma pessoa negra chegar ao hospital com ferimento devido à arma de fogo,

o discurso vai ser assim: você sabe o que que fulano fez? Você já descobriu? Você já conversou a familia? Que que fulano faz? Agora... se é uma pessoa branca, se é um branco a pergunta já tem um discurso diferente: "Nossa, coitado, que que será que aconteceu?". (...) e eu estou falando de uma dessas situaçóes que a gente está acostumado no pronto socorro, ai você já quer saber o que fez. Se é um branco, você quer saber o que sofreu. (A.).

Se, para A., podem-se observar comportamentos preconceituosos no atendimento às pessoas negras, para os outros seis profissionais isso não foi percebido. Por outro lado, apontam, em sua totalidade, que tais coletivos ocupam postos de trabalhos relacionados aos serviços gerais e enfermagem, como técnicos. Tais dados condizem com as pesquisas e estudos a respeito da 
discriminação no mercado de trabalho no que diz respeito às relaçóes raciais. (IPEA, 2000; BENTO, 2000; COUTINHO, 2006).

De fundamental importância para o combate ao racismo nas instituições de saúde é a informação e o debate sobre o tema, o que permite a construção de um olhar atento a tais práticas. Mas, se o conhecimento e a reflexão estão ausentes, a consequência é a reprodução incessante dos mecanismos racistas na sociedade brasileira. Essa situação é bem ilustrada quando todos os profissionais psicólogos declararam desconhecer a Lei 9.934 de 26/06/2010, que dispóe sobre a política municipal de promoção da igualdade racial, bem como a Política Municipal de Saúde da População Negra, lançada em 25/04/2008. E, também, nenhum deles soube informar quais são as açóes afirmativas desenvolvidas pela Secretaria Municipal de Saúde para alcançar e promover a equidade nesse campo; sobre o conhecimento dos dados relativos à utilização do quesito cor na produção de informações epidemiológicas para a definição de prioridades e tomada de decisões quanto à saúde da população negra; sobre os dados que chamam atençáo para o quadro de morbimortalidade da população negra; nem sobre os instrumentos de avaliação do Programa de Anemia Falciforme (PAF) na rede de serviços do município.

Também, de forma unânime, os profissionais psicólogos afirmaram que não existe nos centros de saúde em que trabalham nenhuma preocupação nesse sentido, que o tema nunca foi colocado na pauta das açóes direcionadas para treinamentos, formação e discussão sobre a saúde da população negra. E, ainda, que nunca receberam queixas, por parte dos sujeitos usuários, de discriminação sofrida nos hospitais. Por outro lado, é importante assinalar que cinco dos profissionais entrevistados afirmaram que são comuns as queixas de discriminação recebidas por sujeitos homossexuais.

Sobre a maneira como o racismo pode adoecer as pessoas, apontaram: a "baixa autoestima", "emocionalmente", "psicologicamente", "maior insegurança”, jargóes bem utilizados no campo "psi" e que, em verdade, são bastante vagos. Em nenhuma das entrevistas apareceu o adoecimento psíquico articulado com as relações étnico-raciais advindo da falta de reconhecimento das contribuições das identidades afro-brasileiras para a sociedade.
Nem mesmo o silêncio e a não denúncia dos maus tratos devido à cor - o náo dito - foram interpretados pelos profissionais como possíveis sinais do preconceito e discriminação que recebem os coletivos negros.

A contribuição da psicologia para o combate ao racismo nas instituiçóes de saúde pesquisadas deixou claro, em todas as entrevistas, que a clínica é o espaço para o tratamento de situaçóes que possam surgir e quem envolvam o racismo: a "escuta", "o tratamento bumanizado", "o foco na questão do sujeito", "resgate do ser humano", "estruturar isso com a subjetividade que ele está trazendo", foram termos, de maneira geral, utilizados. Dois dos profissionais participantes da pesquisa disseram que no setor de psicologia em que estão inseridos não existem açôes efetivas e nem preocupação com o tema do racismo e a saúde.

\section{Considerações finais}

A participação da psicologia e dos profissionais psicólogos no combate ao racismo nas instituiçóes de saúde é de inegável importância. Além do fato dessa responsabilidade estar preconizada nos princípios éticos do Conselho Federal, os psicólogos nos centros de saúde estão em contato direto com a população negra, até porque ela é 'SUS-dependente', viabilizando completamente a construção de um campo de reflexôes e açóes em prol dessa questão.

Adicionalmente às ferramentas que a própria disciplina oferece, já trabalham nos hospitais profissionais oriundos de diferentes campos do conhecimento, o que facilita o trabalho conjunto e a atenção focada no que acontece no ambiente com relação aos preconceitos e discriminaçóes contra aqueles coletivos, seja na área da gestão hospitalar ou nas relaçóes com os usuários.

Apesar disso, pode-se afirmar que este estudo apontou para uma total ausência de percepção do racismo institucional nos centros de saúde em que os profissionais psicólogos trabalham. A existência do racismo no país foi um dado confirmado por todos os entrevistados, mas não foi possível localizá-lo nas relaçóes de trabalho, salvo pelas pequenas observaçóes apontadas. 
Essa situação pode ser pensada a partir da formação dos cursos de psicologia, que só muito recentemente têm colocado o tema em pauta; na falta de diálogo da psicologia social com a psicanálise; na psicanálise, que, de forma geral, insiste em reduzir os sujeitos a questóes psíquicas, tratando a subjetividade de maneira individualista; na antiga e persistente dificuldade dos profissionais psicólogos de marcar posiçôes fortes dentro dos centros de saúde.

Por outro lado, o que se percebe na fala dos entrevistados é a reprodução da naturalização de ideologias que foram construídas para manter as relações interétnicas e raciais sem conflitos, propositoras de igualdade que na realidade não existe.

Dessa forma, a proposta se direciona para os Conselhos de Psicologia, em todos os âmbitos, no sentido de implementar açóes que sensibilizem a categoria que atua no sistema de saúde com o objetivo se criar instrumentos concretos de superaçáo da iniquidade nesse campo.

\section{Referências}

BARDIN, L. Análise de conteúdo. Lisboa: Edições 70, 2002.

CÓDIGO DE ÉTICA DO PROFISSIONAL PSICÓLOGO. 2005. Disponível em: <http://site.cfp.org.br/wp-content/uploads/2012/ 07/codigo_etica.pdf>. Acesso em: 25 out. 2012.

BENTO, M.A.S. Branqueamento e branquitude no Brasil. In: CARONE, I.; BENTO, M.A.S. Psicologia social do racismo. Petrópolis: Vozes, 2003.

Igualdade e diversidade no trabalho. In: BENTO, M.A.S Ações afirmativas e diversidade: desafios e possibilidades. São Paulo: Casa do psicólogo, 2000

CARONE, I. Breve Histórico de uma pesquisa psicossocial sobre a questão racial brasileira. In: CARONE, I.; BENTO, M.A.S. Psicologia social do racismo. Petrópolis: Vozes, 2003.

COUTINHO, M.L.P. Discriminação no trabalho: mecanismos de combate e de promoção da igualdade de oportunidades. OIT, Brasília, 2006.

CUNHA, E.M.G.P. Raça: aspecto esquecido na iniquidade em saúde no Brasil: In: BARATA, R.C.B. (org). Equidade e Saúde: contribuições da epidemiologia. Rio de Janeiro: FIOCRUZ/ABRASCO, n.1, 1997. p.219-234. (Série Epidemiológica)

HONNETH, A. Luta pelo reconhecimento: a gramática moral dos conflitos sociais. Rio de Janeiro: Editora 34, 2003.

INSTITUTO DE PESQUISA ECONÔMICA APLICADA (IPEA). Retrato das desigualdades de gênero e raça. Análise preliminar dos dados. 3. ed. Brasília, setembro de 2008.
- perfil da discriminação no mercado de trabalho homens negros, mulheres brancas e negras. Texto para discussão 769. Diretoria de Estudos Sociais do IPEA. Brasília, nov.2000.

LOPES, F. Experiências desiguais ao nascer, viver, adoecer e morrer: tópicos em saúde da população negra no Brasil. Saúde da População Negra no Brasil - contribuições para a promoção da equidade. Brasília: Fundação Nacional de Saúde, 2005.

LOUREIRO, M.M; ROZENFELD, S. Epidemiologia de internações por doença falciforme no Brasil. Revista de Saúde Pública, São Paulo, v.39, n.6, p.943-949, dez. 2005.

MAIO, M.C.; MONTEIRO, S. Tempos de racialização: o caso da "saúde da população negra" no Brasil. História, ciência, saúde Manguinhos, Rio de Janeiro, v.12, n.2, ago.2005. Disponível em: $<$ http://www.scielo.br/scielo.php?script=sci_arttext\&pid=S0104$59702005000200010 \&$ lng $=e n \& n r m=i s o>$. Acesso em: 8 maio 2012.

MINAYO, M.C.S. O desafio do conhecimento. São Paulo: Hucitec, Rio de Janeiro: Abrasco, 1993.

OLIVEIRA, F. Saúde da população negra. Brasília: OPAS, 2002.

PLANO MUNICIPAL DE PROMOÇÃO DA IGUALDADE RACIAL. Belo Horizonte: Prefeitura de Belo Horizonte: 2009.

POLÍTICA NACIONAL DE SAÚDE INTEGRAL DA POPULAÇÃO NEGRA. Brasília: SEPPIR, 2007.

SAÚDE DA POPULAÇÃO NEGRA NO BRASIL. Contribuições para a promoção da equidade. Brasília: Fundação Nacional de Saúde, 2005. 
SILVA, J. A promoção à igualdade racial em 2006 e o Programa de Combate ao Racismo Institucional. In: JACCOUD, L. (Org.). A construção de uma política de promoção da igualdade racial: uma análise dos últimos vinte anos. Brasília: IPEA, 2009, p.147-170.

SILVA, M.O.; FIGUEIREDO, N.D. Crítica sobre políticas, ações e programas de saúde implementados no Brasil. Saúde da População Negra no Brasil - contribuições para a promoção da equidade. Fundação Nacional de Saúde. Brasília, 2005, p.387-437.

SOUZA, J. A ralé brasileira: como é e como vive. Belo Horizonte: UFMG, 2009.

A gramática social da desigualdade brasileira. Revista Brasileira de Ciências Sociais. V.19, n.54, p. 79-97, fev, 2004
WERNECK, J. Iniquidades raciais em saúde e políticas de enfrentamento: as experiências do Canadá, Estados Unidos, África do Sul e Reino Unido. Saúde da população negra no Brasil. Contribuições para a promoção da equidade. Brasília: Funasa: Ministério da Saúde, 2005.

Recebido para publicação em outubro de 2012

Versão final em agosto de 2013

Conflito de interesse: não houve

Suporte financeiro: inexistente 